\title{
Accuracy of HPV E6/E7 mRNA examination using in situ hybridization in diagnosing cervical intraepithelial lesions
}

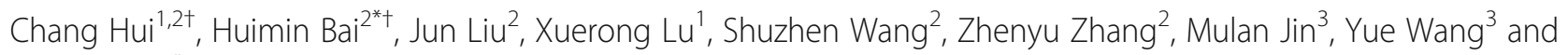
Yuzhen Liu ${ }^{*}$

\begin{abstract}
Background: The consistency of pathologists in the diagnosis of cervical intraepithelial neoplasia (CINs) is not ideal, especially between low- and high-grade squamous intraepithelial lesions (LSIL and HSIL). This study was aimed to explore efficient strategies for the grading of CINs.

Methods: The medical records of patients with high risk human papillomavirus (HR-HPV) infections who had underwent cervical biopsy or conization from April 2018 to April 2019 in Beijing Chao-Yang Hospital were collected and examined. The HR-HPV E6/E7 mRNA in the tissues of patients with CINs was detected using RNAscope chromogenic in situ hybridization (RISH). Immunohistochemistry (IHC) was performed to evaluate the expression of p16INK4a (P16) and Ki67.

Results: HR-HPV E6/E7 mRNA signals were detected in 3/27 (11.1\%) of CIN 1, and in 32/33 (97.0\%) of CIN 2/3. Most of the staining patterns $(27 / 32,84.4 \%)$ had a full-thickness epithelial layer staining with weak-to-strong nuclear and cytoplasmic dot-like signals in CIN 2/3, and there were also few special staining patterns that were significantly different from the others. A number of indicators were compared between LSIL and HSIL. There were statistically significant differences in E6/E7 mRNA, p16, Ki67 and cytology between the two groups $(P<0.05)$. According to the logistic regression analysis, merely E6/E7 mRNA positivity was significantly associated with CIN2/3 (OR: $52.53,95 \% \mathrm{Cl}, P<0.05$ ). In the detection of CIN 2/3, the sensitivity and specificity of HPV E6/E7 mRNA alone was not significantly inferior to that of its different combinations with Ki67, p16 and cytology (all, $P>0.05$ ).

Conclusions: RISH is efficient in grading of CINs. The HPV E6/E7 mRNA expression might reflect the phase HPV infections, and its positive pattern might predict the development direction of CINs, providing the possibility to realize more accurate treatments for patients.
\end{abstract}

Keywords: Cervical intraepithelial neoplasia, CIN, Diagnostic accuracy, E6/E7 mRNA, In situ hybridization

\footnotetext{
*Correspondence: lyz0412@wfmc.edu.cn; bhmdoctor@sina.com

${ }^{\dagger}$ Chang Hui and Huimin Bai contributed equally to this work.

${ }^{1}$ Department of Obstetrics and Gynecology, Affiliated Hospital of Weifang

Medical University, No. 2428, Yuhe Road, Weifang 261042, China

${ }^{2}$ Department of Obstetrics and Gynecology, Beijing Chao-yang Hospital,

Capital Medical University, No.8, North Road of Workers Stadium, Chaoyang

District, Beijing 100020, China

Full list of author information is available at the end of the article
}

\section{$\triangle B M C$}

(c) The Author(s). 2021 Open Access This article is licensed under a Creative Commons Attribution 4.0 International License, which permits use, sharing, adaptation, distribution and reproduction in any medium or format, as long as you give appropriate credit to the original author(s) and the source, provide a link to the Creative Commons licence, and indicate if changes were made. The images or other third party material in this article are included in the article's Creative Commons licence, unless indicated otherwise in a credit line to the material. If material is not included in the article's Creative Commons licence and your intended use is not permitted by statutory regulation or exceeds the permitted use, you will need to obtain permission directly from the copyright holder. To view a copy of this licence, visit http://creativecommons.org/licenses/by/4.0/ The Creative Commons Public Domain Dedication waiver (http://creativecommons.org/publicdomain/zero/1.0/) applies to the data made available in this article, unless otherwise stated in a credit line to the data. 


\section{Background}

Cervical cancer (CC) is one of the most common malignant tumors in women. Its incidence and mortality ranks fourth among malignant tumors in women, and approximately 300,000 women die due to this tumor every year [1]. A large number of studies have shown that HR-HPV persistent infection is the major tumorigenesis factor for $\mathrm{CC}$ and cervical intraepithelial neoplasia (CIN) [2]. CIN is the precursor lesion of CC, and is graded as 1, 2 and 3 [3]. The transformation from CIN to $\mathrm{CC}$ undergoes a gradual process, which requires an average of 5-14 years, when undetected or untreated [4]. Thus, early-diagnosis and timely-intervention are the key to reduce its incidence and mortality. The clinical management strategies for CINs have been based on the pathological diagnosis. However, the consistency of pathologists in the diagnosis of CINs remains unideal. Especially for CIN2, the reported diagnostic consistency of independent pathologists is less than $50 \%[5,6]$. Due to the lack of reproducible histological distinctions and accurate biomarkers that could efficiently define the distinct intermediate state of CIN2, a two-tier system of low- and high-grade squamous intraepithelial lisions (LSIL and HSIL, respectively) has been recommended. Hence, CIN2 is no longer regarded as an independent histological subtype [3].

P16, as a multi-tumor suppressor gene, is directly involved in the regulation of the cell cycle, inhibiting the activity of cyclin-dependent protein kinase CDK4/CDK6 [7]. P16 overexpression has been detected in CINs and $\mathrm{CC}$, and its level increases with the grade of the disease [8]. P16 has been used as a marker to improve the diagnostic consistency of CINs between different pathologists [9]. However, the natural history of p16, which present as positive in CIN1 and negative in CIN3 under certain circumstances, is still not well established [10, 11]. Thus, the downgrading or upgrading of diagnoses has been unavoidable, leading to under- or overtreatment for this patient group $[4,11]$.

The overexpression of HR-HPV E6/E7 genes is the key causative factor for CINs and CC [12]. The mRNA, as the direct transcription production of the gene, could accurately reflect its transcription activity. HR-HPV E6/E7 mRNA detection could effectively reduce the false positive rate of HPV DNA examinations due to the HPV transient infection. HPV E6/E7 mRNA (Aptima) detection with the technology of transcription mediated amplification (TMA) has been widely used in the screening of CC. However, this technology is not suitable for detecting samples of formalin-fixed paraffin-embedded (FFPE) tissues due to its low sensitivity, complicated operation, and other technical factors [13]. In situ hybridisation (ISH) is an established method for the detection and visualization of specific nucleic acid sequences
(DNA and RNA) in tissue sections, cytological preparations, and whole organisms [14]. RNAscope technology is a new generation of single-molecule RNA ISH analysis technology. A novel probe design strategy and a hybridization-based signal amplification system to simultaneously amplify signals and suppress the background are applied during this procedure. The mRNA expression can be observed at the single-cell level under a standard bright-field microscope. This technology has the advantages of easy operation and high sensitivity [15]. RNAscope brings the benefits of in situ analysis to RNA biomarkers, and may enable the rapid development of RNA ISH-based molecular diagnostic assays. Several researchers have demonstrated that RNA ISH is more sensitive, when compared to DNA ISH, in terms of detecting HPV in oropharyngeal cancers $[16,17]$. In the present analysis, RNA ISH was performed to detect the level of HR-HPV E6/E7 mRNA in the FFPE tissue of patients with CINs. The accuracy of this procedure in the grading of CINs was also evaluated.

\section{Methods \\ Specimens}

The medical records of patients with CINs detected by cervical biopsy or conization from April 2018 to April 2019 in Beijing Chao-Yang Hospital were retrospectively reviewed. All outpatients within $19-65$ years old were routinely inquired whether they recently received CC screening examination. If not, cytology (HOLOGIC, USA) and HPV detection (Fluorometric Real-time PCR, Shanghai ZJ Bio-Tech, China) were performed under oral informed consent. The results for the cervical cytology were reported using the 2014 Bethesda (TBS) system [18]. According to the 2012 American Society for Colposcopy and Cervical Pathology (ASCCP) revised guidelines for the treatment of CC screening abnormal results [19], patients with abnormal cytology (worse than atypical squamous cells of undetermined significance, $>$ ASC-US or continuous ASC-US), HR-HPV16/18 positive testing, persistent infection (more than one year) of the other subtypes of HR-HPV, ASC-US and HR-HPV positive testing, and/or visible suspicious lesions were scheduled for colposcopy. A biopsy was performed, when necessary. Most of the patients who were pathologically diagnosed with HSIL underwent physical therapy or loop electrosurgical excision procedure (LEEP). For young women with desire for fertility, patients with CIN2 were followed up when there was a satisfactory colposcopy which means that the cervix and squamocolumnar junction (SCJ) is fully visualized [19].

Patients with CIN1, CIN2 and CIN3 were compiled for further evaluation. Patients with concurrent invasive $\mathrm{CC}$, which is a simultaneous or subsequent primary malignant tumor in other parts of the body, and incomplete 
medical records were excluded. Furthermore, patients with insufficient tissues for the ISH or IHC examination were also excluded.

The patient clinical data, which included age at diagnosis, smoking history, drinking history, age at first intercourse, sex partners, education, fertility status, menopausal status, body mass index (BMI), monthly income, cytology, HR-HPV detection, surgical method, pathological diagnosis and screening history, was collected and evaluated. The BMI was calculated by dividing the weight in kilograms by the height in meters squared. Subjects who smoked at least one cigarette a day and continuously for more than six months were considered positive for smoking history. Drinking at least once a month, including social engagements, was considered positive for drinking history.

The H\&E slides of these patients were reviewed by two independent gynecologic pathologists, who were blind to the results. Any disagreements between these two reviewers were discussed and resolved. If a disagreement could not be resolved, a third review would be conducted until a consensus diagnosis (at least a twoway agreement) is reached. The histological classification criteria of CINs were referred to the World Health Organization (WHO) classification criteria for cervical intraepithelial lesions in 2014 [3]. For CIN1, the undifferentiated cells extended no more than one-third of the way up the epithelium. Nuclear hyperchromasia nuclear membrane irregularities and few mitotic features are usually present. Furthermore, koilocytosis can be observed. For CIN2, the undifferentiated cells were confined in the lower $2 / 3$ of the epithelium, but exceeding the criteria for LSIL. Furthermore, these tended to more obviously present with nuclear atypia and mitotic features. For CIN3, differentiation and stratification may be totally absent, or only present in the superficial quarter of the epithelium. Nuclear abnormalities could be observed in the full-thickness epithelium. However, the lesion did not break through the basement membrane.

Five 4- $\mu \mathrm{m}$-thick sections were cut from the FFPE tissue. Hematoxylin and eosin (H\&E), RISH and IHC staining were respectively performed.

\section{RNA RISH}

The RNAscope HR $18 \mathrm{HPV}$ assay is designed to detect the E6/E7 RNA for 18 HR HPV genotypes (HPV 16, 18, $26,31,33,35,39,45,51,52,53,56,58,59,66,68,73$ and 82 ). The RNAscope ${ }^{\circ}$ 2.5HD probes and detection kit were purchased from Advanced Cell Diagnostics (ACD, Hayward, USA). The assay was performed according to supplier's instructions (ACD). Pretreatment: After being de-paraffinized and dehydrated, these sections were serially treated with the Pre-Treatment 1 solution and PreTreatment. Overnight, Pre-Treatment 3 was performed.
Hybridization: The sections were hybridized in the HR 18 HPV hybridization solution without a cover slip in a HybEZ Oven (ACD, Hayward, USA). Signal amplification: The hybridized probe was performed through the serial application of Amp 1-6. Visualization: Diaminobenzidine $(\mathrm{DAB})$ was used to demonstrate the amplified signal. The sections were counterstained with H\&E, dehydrated with graded ethanol and xylene, and mounted with Cytoseal.

The staining data was recorded with the presence of dark brown, nuclear + and dot-like cytoplasmic+/-. The positivity pattern was recorded according to thickness of the epithelial staining, the presence and amount of diffuse, and/or the punctate nuclear staining and cytoplasmic staining, as well as the signal intensity. Morphologically, normal epithelia in the FFPE block were used as the internal negative control. A positive control was added to ensure that the dyeing process of the slides was successful. If the positive control did not show a positive staining, the batch of slides were considered as invalid.

The RISH slides were scanned using an automatic digital pathological slide scanner at $20 \times$ magnification. The expression intensity of the HR-HPV E6/E7 mRNA was analyzed using the StrataQuest software. The nuclei were identified and screened by H\&E staining channels. The effective nucleus, which was a single effective nucleus that eliminated the identified oversized adherent nuclei and undersized cell fragments, was used as the core to identify the areas with DAB staining signals within the cell range. Then, the E6/E7 mRNA expression of a single cell was quantified using the software, according to the DAB staining intensity and number of cells in the lesion area.

\section{IHC was performed to detected the expression level of P16 and Ki67}

IHC was performed using the antibodies of P16 (clone: G175-405, ZSGB-BIO, China) and Ki67 (clone: MIB1, ZSGB-BIO, China), respectively, according to manufacturer's instructions. Then, the sections were deparaffinized and dehydrated. The antigen retrieval was performed by boiling the slides with the ethylene diamine tetraacetic acid (EDTA) Antigen Retrieval solution ( $\mathrm{pH}$ 9.0) in a pressure cooker for $15 \mathrm{~min}$. After blocking the endogenous peroxidase with $\mathrm{H}_{2} \mathrm{O}_{2}$, the sections were incubated with the antibodies. Then, the secondary antibody reagent was performed. The reaction was detected by $D A B$ and counterstained with H\&E. A positive control slide was used to ensure the validity of the staining procedure.

Definition of P16 positivity: According to the Lower Anogenital Squamous Terminology (LAST) definition of p16 positivity [3], which calls "block positivity" continuous staining in the nucleus and/or cytoplasm, this was 
extended up from the basal layer through at least onethird of the epithelium. Definition of Ki67 positivity: Nuclear staining only and continuous staining, and this extended up from the basal layer through the lower third of the epithelium.

\section{Statistical analyses}

SPSS (21.0) was used for the statistical analysis. The rate and percentage of expression was used to describe the general situation of the study subject. HSIL was used as the clinical endpoint of the disease to evaluate the diagnostic efficiencies of HPV E6/E7 mRNA ISH, P16 and P16/Ki67 on CINs, and calculate the sensitivity and specificity of these various detection methods. Chi-square was used to test for differences in expression rate, sensitivity and specificity. Binary logistic regression was used to calculate the OR and $95 \%$ confidence interval (CI), which describes the risk factors associated with CINs. A $P$-value of $<0.05$ was considered statistically significant.

\section{Results}

A total of 67 patients, who underwent cervical biopsy or LEEP, were pathologically diagnosed with CINs during the study period. Five patients with concurrent invasive carcinoma were excluded due to invasive carcinoma. Two patients with insufficient tissue for ISH or IHC were excluded. Finally, a total of 60 patients, who met the inclusion criteria, were included for further evaluation. The clinicopathological characteristics of these patients are presented in Table 1 . The mean age at diagnosis was $33.0 \pm 8.8$ years old (range: $18-65$ years old). Furthermore, three women (5\%) were postmenopausal, $26(43.3 \%)$ women were nulliparous, and 34 (56.7\%) women were detected with abnormal cytology. In addition, positive p16 was detected in $36(60 \%)$ women, positive Ki67 was detected in 42 (70\%) women, and LSIL was detected in 27 (45\%) women. The remaining $33(55 \%)$ women were diagnosed with HSIL, which included CIN2 (17 cases) and CIN3 (16 cases), respectively. Positive HPV E6/E7 mRNA was identified in 35 (58.3\%) women, which included LSIL (three cases) and HSIL (32 cases), respectively. One patient with HSIL presented with negative HPV E6/E7 mRNA.

The characteristics of the HPV E6/E7 mRNA staining of patients presented with an E6/E7 mRNA positive expression and LSIL disease, as presented in Fig. 1. The nucleus and cytoplasm in the full-thickness epithelial layer presented with dot-like signals, and different epithelial layers presented with diffuse nuclear signals. For most of the $(27 / 33,81.8 \%)$ patients with HSIL disease, the positive staining of HPV E6/E7 mRNA presented with weak-to-strong nuclear and cytoplasmic dot-like signals within full-thickness epithelial layer (Fig. 2). In addition, the positive patterns of CIN2 and CIN3 were respectively observed, According to the locations of the signals, the following expression was used for recording (Table 2): For CIN2, signals extending to the basal, up to the surface epithelium, were observed in $62.5 \%$ of the patients; signals confined in the upper middle epithelial layers were observed in $31.3 \%$ of the patients; signal staining confined in the lower middle epithelial layers was observed in $6.2 \%$ of the patients. For CIN3, a case of indeterminate depth of expression was excluded due to inadequate epithelium. Signals extending to the basal, up to the surface epithelium, were observed in $66.7 \%$ of the patients; signals confined in the upper middle epithelial layers were observed in $20.0 \%$ of the patients; signal staining confined in the lower middle epithelial layers were observed in $13.3 \%$ of the patients. Although there were some differences between these, there was no statistical significance $(P>0.05)$. The analysis of the StrataQuest digital images revealed that there was no statistical difference in single-cell intensity or the percentage of positive cells between CIN2 and CIN3 (Table 3, $P>0.05$ ).

The potential predictors for HSIL disease were evaluated in Tables 4 and 5 . In the univariate analysis, positive E6/E7 mRNA, p16, Ki67 and abnormal cytology ( $\geq$ ASC-US) were statistical risk factors for $\operatorname{HSIL}(P=0.000$, $0.000,0.000$ and 0.024 , respectively). Positive E6/ E7mRNA was a risk factor for HSIL in the logistic regression analysis $(P=0.011)$, with an OR of 3.961 , indicating that HSIL Positive RNA was 3.961 times more likely than negative RNA. For patients with positive E6/ E7 mRNA expression, the risk rate of HSIL reached as high as $91.4 \%$, when compared to the rate of $4.0 \%$ for those with negative E6/E7 mRNA expression.

The sensitivity and specificity for the HPV E6/E7 mRNA was $96.97 \%$ and $88.89 \%$, respectively (Table 6). The sensitivity and specificity for the HPV E6/E7 mRNA alone were statistically better, when compared to p16 and p16/Ki67. However, these were not significantly inferior to the different combinations (all, $P>0.05$ ).

\section{Discussion}

The present study had three major findings: (1) HPV E6/E7 mRNA was highly expressed in HSIL, and its positive expression obviously increased with the grade of the lesion. (2) For the detection of HSIL, the sensitivity and specificity of HPV E6/E7 mRNA ISH were better than p16 and p16/Ki67, but were not significantly inferior to the other different combinations. (3) The HPV E6/E7mRNA positive expression might reflect the phase of HPV infection, and its expression pattern may predict the development direction of CINs.

In the present study, HPV E6/E7 mRNA, Ki67, p16 and cytology were the predictors of HSIL in the univariate analysis. Cytology examination (ThinPrep cytology 
Table 1 Clinicopathological characteristics of the 60 patients with CINs

\begin{tabular}{|c|c|c|}
\hline Parameters & Numbers & Percent \\
\hline Age at diagnosis, (Mean;range) & $33.0 \pm 8.8$ & $18-65$ \\
\hline \multicolumn{3}{|l|}{ Smoking history } \\
\hline Yes & 5 & $8.3 \%$ \\
\hline No & 55 & $91.7 \%$ \\
\hline \multicolumn{3}{|l|}{ Drinking } \\
\hline Yes & 10 & $16.7 \%$ \\
\hline No & 50 & $83.3 \%$ \\
\hline \multicolumn{3}{|l|}{ Education } \\
\hline Primary & 1 & $1.7 \%$ \\
\hline Secondary & 20 & $38.3 \%$ \\
\hline College and above & 36 & $60.0 \%$ \\
\hline \multicolumn{3}{|l|}{ Fertility status } \\
\hline Nulliparous & 26 & $43.3 \%$ \\
\hline Pluriparous & 34 & $56.7 \%$ \\
\hline \multicolumn{3}{|l|}{ Menopausal status } \\
\hline Pre-menopausal & 57 & $95 \%$ \\
\hline Post-menopausal & 3 & $5 \%$ \\
\hline \multicolumn{3}{|l|}{ BMI } \\
\hline Normal(18.5-25) & 46 & $76.7 \%$ \\
\hline Overweight(> 25) & 6 & $10.0 \%$ \\
\hline Underweight $(<18.5)$ & 8 & $13.3 \%$ \\
\hline \multicolumn{3}{|l|}{ Monthly income } \\
\hline$\leq 10000$ & 34 & $56.7 \%$ \\
\hline$>10000$ & 26 & $43.3 \%$ \\
\hline \multicolumn{3}{|l|}{ Presentation } \\
\hline Contact bleeding & 3 & $5 \%$ \\
\hline Symptomless & 57 & $95 \%$ \\
\hline \multicolumn{3}{|l|}{ Screening history } \\
\hline Ever & 27 & $45 \%$ \\
\hline Never & 33 & $55 \%$ \\
\hline Age at first intercourse (Mean;range) & $22.0 \pm 2.6$ & $18-31$ \\
\hline \multicolumn{3}{|l|}{ Sex partners } \\
\hline One & 42 & $70.0 \%$ \\
\hline More than one & 18 & $30.0 \%$ \\
\hline \multicolumn{3}{|l|}{ Referral Cytology } \\
\hline NILM & 26 & $43.3 \%$ \\
\hline ASC-US & 12 & $20.0 \%$ \\
\hline ASC-H & 5 & $8.3 \%$ \\
\hline LISL & 9 & $15.0 \%$ \\
\hline HISL & 8 & $13.3 \%$ \\
\hline \multicolumn{3}{|l|}{ HR-HPV infection } \\
\hline Yes & 60 & $100 \%$ \\
\hline No & 0 & \\
\hline
\end{tabular}

Table 1 Clinicopathological characteristics of the 60 patients with CINs (Continued)

\begin{tabular}{lll}
\hline Parameters & Numbers & Percent \\
\hline CINs detected by & 16 & \\
$\quad$ Biopsy & 44 & $73.3 \%$ \\
LEEP/CKC & & \\
Pathological diagnosis & 27 & $45.0 \%$ \\
CIN1 & 17 & $28.3 \%$ \\
CIN2 & 16 & $26.7 \%$ \\
CIN3 & & \\
E6/E7mRNA & 35 & $58.3 \%$ \\
Positive & 25 & $42.7 \%$ \\
Negative & & \\
p16 & 36 & $60 \%$ \\
Positive & 24 & $40 \%$ \\
Negative & & $70 \%$ \\
Ki67 & & $30 \%$ \\
Positive & 42 & \\
Negative & 18 & \\
\hline
\end{tabular}

Monthly income was the average monthly income of an individual family NILM Negative for intraepithelial lesion or malignancy, ASCUS Atypical squamous cells of undetermined significance, ASC-H Atypical cells cannot exclude high grade, $B M I$ Body mass index

test, TCT) has been widely used for the screening of CC. A large prospective multicenter clinical study revealed that the sensitivity and specificity of TCT is $73 \%-94 \%$ and $58 \%-76 \%$, respectively, in the screening of CC. Compared with the traditional pap smear, the detection of TCT for LSIL and above could reach as high as $73 \%$ [20]. However, this technology is not suitable for the detection samples of FFPE tissues due to its technology [21]. P16 and Ki67 were the most widely used biomarkers for the grading of CINs [22]. Studies have shown that the combination of H\&E and p16 or Ki67 is a good approach to improve the accuracy of the pathological diagnosis of CINs [22, 23]. However, studies have argued that the overexpression of P16 may be closely correlated to the HPV oncoprotein E7 inactivating cellcycle regulation $\mathrm{Rb}$ protein [24]. At present, the specific mechanism is not fully understood, and the correlation between P16 and history of HPV infection remains unclear. P16 expression status cannot accurately predict the potential risk of CINs. Furthermore, the negative expression of p16 does not exclude HPV infection, and p16 positive does not mean HPV infection or HSIL results $[25,26]$. This is consistent with the present data. In the present study, the sensitivity and specificity of p16 to the detection of HSIL was $93.94 \%$ and $81.48 \%$, respectively. In addition, a previous study revealed that p16 is not only expressed in high grade lesions and Caski cervical cancer cells (ATCC ${ }^{\ominus}$ CRM-CRL-1550), but also in 

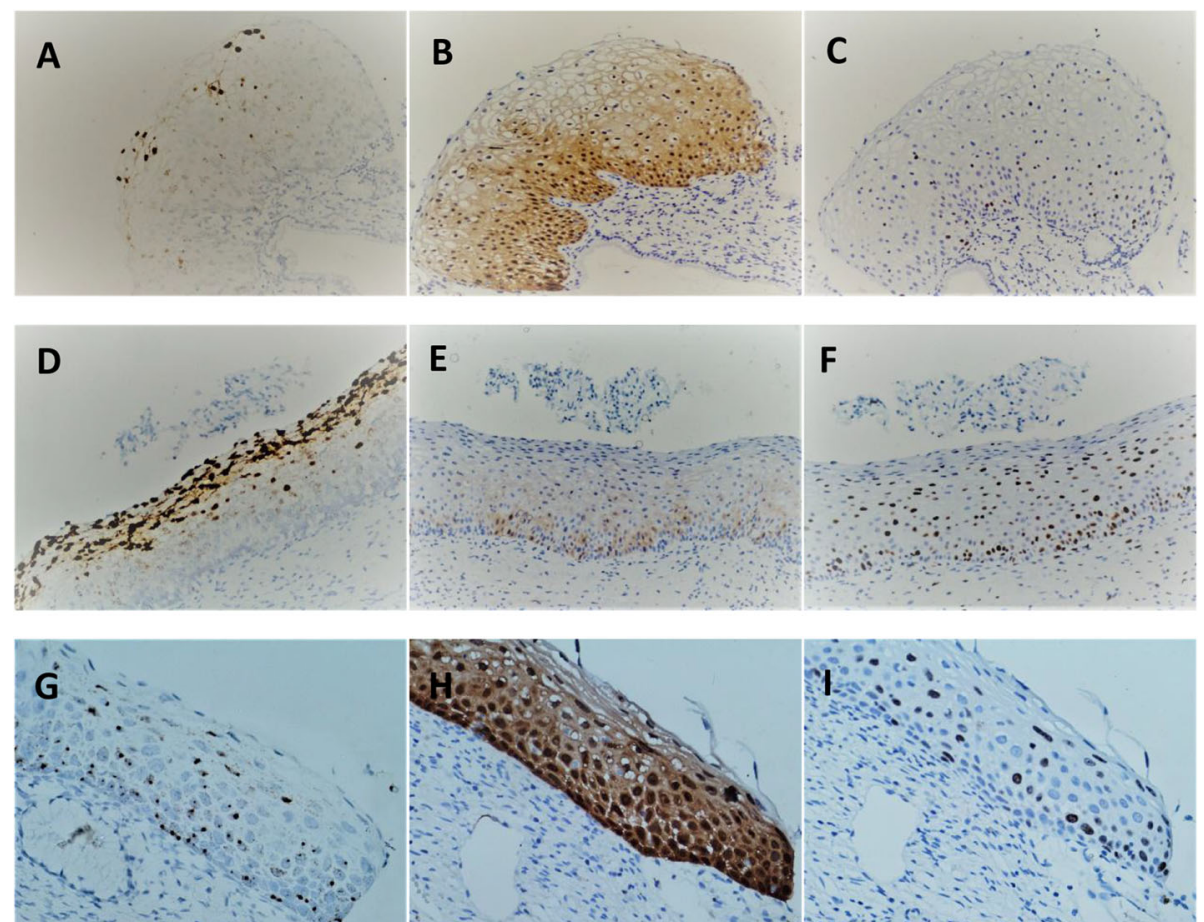

Fig. 1 CIN staining results. The CIN1 specimen (a-c), a HPV E6/E7 mRNA positive, b p16 positive, c Ki67 positive. CIN2 specimen (d-f), d HPV E6/E7 mRNA positive, e p16 negative, the signals were limited in the basal layer. $\mathbf{f}$ Ki67 positive. CIN3 specimen (g-i), $\mathbf{h}$ HPV E6/E7 mRNA positive, i p16 positive, g Ki67 positive
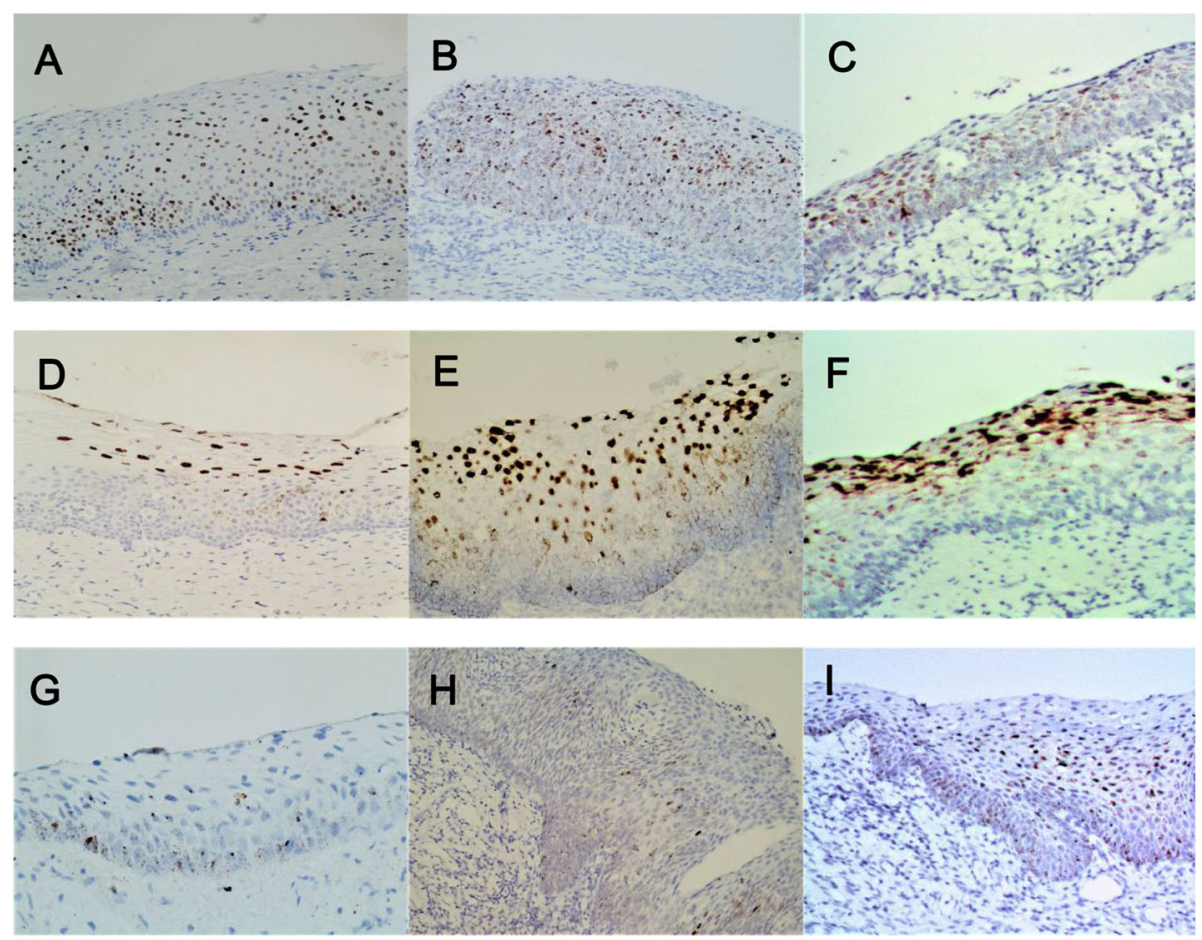

Fig. 2 HPV E6/E7 mRNA staining patterns. According to the locations of the signals: BSE (a-c): basal up to superficial epithelium, UME (d-f): signal staining confined in upper middle epithelial layer. LME (g-i): signal staining confined in the lower middle epithelial layer 
Table 2 Staining patterns of HPV E6/E7 mRNA in situ hybridization in CIN2 and CIN3 n(\%)

\begin{tabular}{lll}
\hline & CIN2+ $(\boldsymbol{n}=\mathbf{1 6})$ & CIN3+ $(\boldsymbol{n}=\mathbf{1 5})$ \\
\hline BSE & $10(62.5)$ & $10(66.7)$ \\
UME & $5(31.3)$ & $3(20.0)$ \\
LME & $1(6.2)$ & $2(13.3)$
\end{tabular}

UME Signals staining confined in upper middle epithelial layers, LME Signals staining confined in lower middle epithelial layers, BSE Signals staining basal up to surface epithelium

normal cervical cells, and the single-cell intensity between CIN cells and Caski cells were similar [27]. Although this result may be due to the reason that the cervix cells from the original generation of culture had the capacity of proliferation, these cells were HPV negative. Hence, the correlation between p16 and HPV infection needs to be further studied. Some studies also reported that the interpretation of p16 was subjective, and that there are no criteria widely accepted for what the exact cut-off point for a positive vs. negative immunohistochemical stain should be $[3,28]$.

As a nuclear proliferation antigen, ki67 is exclusively expressed in the proliferation phase of the cell cycle [29]. Ki67 expression in normal cervical tissues, CIN and cervical cancer tissues gradually increases with the aggravation of the disease. Furthermore, there is a statistical difference in the positive expression between LSIL and HSIL [30]. P16 overexpression occurs only when the cell cycle modulation is disordered, and the cell proliferation becomes abnormal. Under normal physiological conditions, Ki67 and p16 are not simultaneously expressed in the same cell. The co-expression of Ki67 and p16 usually indicates that the cell cycle is out of control, and that abnormal cell proliferation occurs [31]. The use of Ki67 or p16/Ki67 significantly improved the accuracy of the pathological diagnosis of cervical lesions [32]. However, ki67 was overexpressed in inflammation, LSIL, and a variety of benign tumors [33]. ki67 negative expression cannot exclude the existence of HPV infection and CINs, especially LSIL. Studies have also reported that Ki-67 and p16/Ki67 exhibited no marked improvement over p16 alone in the grading of CINs [3, $28]$. Hence, the routine addition of Ki-67 to p16 is not recommended, which was consistent with the results of these present studies. In the present study, the sensitivity and specificity of p16 was $93.94 \%$ and $81.48 \%$ in the detection of HSIL. p16/Ki67 detection was $90.90 \%$ and

Table 3 Comparison between CIN2 and CIN3 in images analysis

\begin{tabular}{|c|c|c|c|c|}
\hline & \multicolumn{2}{|l|}{ Grouping } & \multirow[t]{2}{*}{$t$} & \multirow[t]{2}{*}{$P$} \\
\hline & CIN2 $(n=16)$ & CIN3 $(n=15)$ & & \\
\hline Percentage of positive cells & $44.68 \pm 26.31$ & $43.55 \pm 22.73$ & 0.126 & 0.901 \\
\hline Single-cell Intensity & $27.50 \pm 14.55$ & $19.73 \pm 6.69$ & 1.930 & 0.067 \\
\hline
\end{tabular}

Table 4 The distribution of indicators characteristics and risk factors

\begin{tabular}{|c|c|c|c|}
\hline \multirow[t]{2}{*}{ The baseline data } & \multicolumn{2}{|l|}{ Grouping } & \multirow[t]{2}{*}{$P$} \\
\hline & LSIL $(n=27)$ & HISL $(n=33)$ & \\
\hline \multicolumn{4}{|l|}{ Age } \\
\hline$\leq 33$ & 16 & 17 & \multirow[t]{2}{*}{0.55} \\
\hline$>33$ & 11 & 16 & \\
\hline \multicolumn{4}{|l|}{ Fertility status } \\
\hline No & 25 & 32 & \multirow[t]{2}{*}{0.50} \\
\hline Yes & 2 & 1 & \\
\hline \multicolumn{4}{|l|}{ Cytology } \\
\hline Normal & 16 & 10 & \multirow[t]{2}{*}{0.04} \\
\hline Abnormal & 11 & 21 & \\
\hline \multicolumn{4}{|l|}{ Menopausal status } \\
\hline No & 13 & 13 & \multirow[t]{2}{*}{0.44} \\
\hline Yes & 14 & 20 & \\
\hline \multicolumn{4}{|c|}{ Age at first intercourse } \\
\hline$\leq 22$ & 13 & 20 & \multirow[t]{2}{*}{0.34} \\
\hline$>22$ & 14 & 13 & \\
\hline \multicolumn{4}{|l|}{ Sex partners } \\
\hline 1 & 21 & 21 & \multirow[t]{2}{*}{0.23} \\
\hline$>1$ & 6 & 12 & \\
\hline \multicolumn{4}{|l|}{ Education } \\
\hline Bachelor below & 13 & 11 & \multirow[t]{2}{*}{0.05} \\
\hline Bachelor or above & 14 & 22 & \\
\hline \multicolumn{4}{|l|}{ Monthly income } \\
\hline$\leq 1 w$ & 17 & 17 & \multirow[t]{2}{*}{0.37} \\
\hline$>1 w$ & 10 & 16 & \\
\hline \multicolumn{4}{|l|}{ Smoking history } \\
\hline- & 24 & 1 & \multirow[t]{2}{*}{0.24} \\
\hline+ & 3 & 32 & \\
\hline \multicolumn{4}{|l|}{ Drinking } \\
\hline- & 22 & 2 & \multirow[t]{2}{*}{0.73} \\
\hline+ & 5 & 31 & \\
\hline Screening history & & & \\
\hline Ever & 15 & 18 & 0.94 \\
\hline Never & 12 & 15 & \\
\hline BMI & & & \\
\hline $18.5-25$ & 22 & 24 & 0.72 \\
\hline$>25$ & 2 & 4 & \\
\hline$<18.5$ & 3 & 5 & \\
\hline E6/E7mRNA & & & \\
\hline- & 24 & 1 & 0.00 \\
\hline+ & 3 & 32 & \\
\hline p16 & & & \\
\hline- & 22 & 2 & 0.00 \\
\hline+ & 5 & 31 & \\
\hline Ki67 & & & \\
\hline- & 17 & 1 & 0.00 \\
\hline+ & 10 & 32 & \\
\hline
\end{tabular}


Table 5 Logistic regression model to estimate the association between the risk factors and CIN2/3

\begin{tabular}{llll}
\hline & B & $P$ & OR(95\% C.I.) \\
\hline E6/E7mRNA & 3.961 & 0.011 & 52.53 \\
p16 & 20.452 & 0.998 & 7.62 E8 \\
Ki67 & 1.099 & 0.636 & 3.00 \\
Cytology & 0.777 & 0.602 & 2.18 \\
\hline
\end{tabular}

$85.19 \%$, which was not significantly inferior to p16 alone.

In the early stage of HPV infection, the virus mostly presents as a transient infection or latent infection. The HPV genome is in a free state in the nucleus, and maintains a low replication activity [34]. HPV E6/E7 genes are regulated by E1/E2 genes, and their expression is inhibited during this stage. E6/E7 mRNA is often undetectable. This phase often occurs in normal cervical tissues or CIN1 [24, 35]. In the present analysis, the negative expression of E6/E7 mRNA was identified in $88.9 \%$ of patients with LSIL. In LSIL, the images of the HPV E6/E7 mRNA staining in the nucleus and cytoplasm in the full-thickness epithelial layer presented with dot-like signals, and the different epithelial layers presented with diffuse nuclear signals. During the persistent infection stage, the HR-HPV DNA integrated into the host genome with the disruption and loss of the E2 gene, and this lead to the HPV E6/E7 mRNA overexpression.
This phase mostly occurs in CIN2/3 [24, 35]. In the present study, $97.0 \%$ of patients with HSIL were detected with a positive expression of HPV E6/E7 mRNA. The typical HPV E6/E7 mRNA image of HSIL presented with weak-to-strong nuclear and cytoplasmic dot-like signals within the full-thickness epithelial layer. HPV E6/ E7 mRNA was detected in almost CIN2/3, which exhibited a transition phase. Evans et al. [36] investigated the application of HPV E6/E7 mRNA in situ hybridization in the three-tier grading of CINs. They detected the HRHPV E6/E7 mRNA in 86 cases with CINs lesions, and confirmed that its expression in HSIL was $100 \%$. The assay supports that RISH can be used in CIN histological grading, and that the HPV E6/E7 mRNA expression reflect the phase of the HPV infection. In our study, we added Ki67 and P16/ Ki67 as the control group. The positive E6/E7 mRNA was identified as the only independent risk factor for $\operatorname{HSIL}(P=0.011$,OR: 3.961$)$ in the logistic regression analysis. The sensitivity and specificity of HPV E6/E7 mRNA alone were better than p16, abnormal cytology and Ki67, and were not significantly inferior to the different combinations. E6/E7 mRNA was the direct transcription production of the gene. The expression level of E6/E7 mRNA could accurately reflect the status of the HPV infection. Therefore, it was concluded that RISH can be used for the grading of cervical lesions, and that this has the potential to reflect the different stages of HPV infection.

Table 6 Clinical performance of various indicators for detection of CIN2/3

\begin{tabular}{|c|c|c|c|c|c|c|}
\hline & \multicolumn{2}{|c|}{ Pathological diagnosis } & \multirow[t]{2}{*}{ Sensitivity } & \multirow[t]{2}{*}{$P$} & \multirow[t]{2}{*}{ Specificity } & \multirow[t]{2}{*}{$P$} \\
\hline & $\operatorname{LSIL}(n=27)$ & HISL $(n=33)$ & & & & \\
\hline \multicolumn{7}{|c|}{ E6/E7mRNA } \\
\hline+ & 3 & 32 & $96.97 \%$ & 0.555 & $88.89 \%$ & 0.444 \\
\hline- & 24 & 1 & & & & \\
\hline \multicolumn{7}{|l|}{ p16 } \\
\hline+ & 5 & 31 & $93.94 \%$ & 0.555 & $81.48 \%$ & 0.444 \\
\hline- & 22 & 2 & & & & \\
\hline \multicolumn{7}{|c|}{ p16/Ki67 } \\
\hline+ & 4 & 30 & $90.91 \%$ & 0.302 & $85.19 \%$ & 0.685 \\
\hline- & 23 & 3 & & & & \\
\hline \multicolumn{7}{|c|}{ E6/E7mRNA/p16 } \\
\hline+ & 2 & 30 & $90.91 \%$ & 0.302 & $92.59 \%$ & 0.639 \\
\hline- & 25 & 3 & & & & \\
\hline \multicolumn{7}{|c|}{ E6/E7mRNA/Ki67 } \\
\hline+ & 3 & 31 & $93.94 \%$ & 0.555 & $88.89 \%$ & 1.000 \\
\hline- & 24 & 2 & & & & \\
\hline \multicolumn{7}{|c|}{ E6/E7mRNA/p16/Ki67 } \\
\hline+ & 2 & 29 & $87.88 \%$ & 0.163 & $92.59 \%$ & 0.639 \\
\hline- & 25 & 4 & & & & \\
\hline
\end{tabular}


The progressing risk of HSIL was significantly higher than that of LSIL. Furthermore, approximately a third of the patients could naturally regress, especially for CIN2 in young women, and this natural regression increased with the extension of time [37]. Most young women are eager to have children, and unnecessary clinical intervention may impair cervical function, lead to infertility or other cervix related problems, and impose an unnecessary financial burden [38]. For CIN2, HPV E6/E7 mRNA were detected in $94.1 \%$ of patients. Furthermore, signals extending to the basal, up to the surface epithelium, were observed in $62.5 \%$ of the patients, and signals confined in the upper middle epithelial layers were observed in $31.3 \%$ of the patients. For CIN3, a case of indeterminate depth of expression was excluded due to inadequate epithelium. HPV E6/E7 mRNA were detected in $100 \%$ of the patients. Furthermore, signals extending to the basal, up to the surface epithelium, were observed in $66.7 \%$ of the patients, and signals confined in the upper middle epithelial layers were observed in $20.0 \%$ of the patients. Although there were some differences between these, there was no statistical significance. The intensity of single cells and the percentage of positive cells between CIN2 and CIN3 were compared using the StrataQuest digital image analysis software. The results revealed that there was no statistical significance. These data support the 2-tiered system with LSIL and HSIL. According to the understanding of HPV biology, the biological behavior between CIN2 and CIN3 is indistinguishable [3, 39]. In the 2-tiered system, LSIL reflected the transient HPV infection, while HSIL reflected the persistent HPV infection, which has the potential to progress to CC. In addition, it was observed in two special samples that the E6/E7 mRNA positive patterns were limited in the basal layer with a weak signal in HSIL, which was significantly different from the others. Studies have shown that HPV E6/E7 mRNA is usually highly expressed in HSIL [20, 34]. However, the HPV E6/ E7mRNA of the two samples were expressed at a low level, which reflects that the lesion might be in the phase of regression. At the same time, one sample of HSIL presented with negative expression. It was speculated that the reasons might be, as follows: (1) the lesion was in the phase of regression; (2) the possibility of mRNA degradation in tissue sections; (3) the HPV test may be false positive. HPV E6/E7mRNA directly reflects the state of HPV transcription. Hence, it was speculated that the RISH positive pattern might predict the development direction of CINs, which is worthy of further investigation.

Although the present study has some limitations, which included the relative small sample size and insufficient follow-up data, the present data provides an objective and convincing method to assist in the grading of cervical lesions.

In summary, the data of the present study support the view that HPV E6/E7 mRNA ISH can be used to assist in the grading of CINs. HPV E6/E7 mRNA positive expression might reflect the phase of the HPV infection, and its positive pattern may predict the development direction of CINs, which could provide the possibility to realize a more accurate treatment approach for patients. There is a huge potential value in pathological diagnosis of CINs with HPV E6/E7 mRNA ISH, which is worthy of further investigation.

\section{Abbreviations \\ ACD: Advanced Cell Diagnostics; ASC-H: Atypical cells cannot exclude high grade; ASC-US: Atypical squamous cells of undetermined significance; ASCCP: American Society for Colposcopy and Cervical Pathology; BMI: Body mass index; CIN: Cervical intraepithelial neoplasias; CKC: Cold knife conigation; CAP: The College of American Pathologists; DAB: Double Amino benzidine; FFPE: Formalin-fixed paraffin-embedded; HE: Hematoxylin- eosinstaining; HSIL: High-grade squamous intraepithelial lesion; HPV: Human papilloma virus; HR-HPV: High risk-human papilloma virus; HC-2: Hybrid capture-2; ISH: In situ hybridization; LAST: Lower Anogenital Squamous Terminology; LSIL: Low-grade squamous intraepithelial lesion; LEEP: Loop electrosurgical excision; NILM: Negative for intraepithelial lesion or malignancy; RISH: RNAscope chromogenic in situ hybridization; \\ SCJ: Squamocolumnar junction; TMA: Transcription mediated amplification}

\section{Acknowledgements}

This work is supported by Natural Science Foundation (No.81972424, No.81702551)

\section{Authors' contributions}

$\mathrm{CH}, \mathrm{HM}$ B, and $\mathrm{YZ} \mathrm{L}$ : conception and design of the study, assembly, analysis and interpretation of the data, and manuscript writing. J L, XR L, SZ W, ZY Z, $M L J, Y W$, and $Z Y Z$ : provision of study materials, analysis and interpretation of the data. The author(s) read and approved the final manuscript.

\section{Availability of data and materials}

The datasets used and/or analysed during the current study are available from the corresponding author on reasonable request.

Ethics approval and consent to participate

The study protocol was approved by the ethics committee at the Beijing Chao-Yang Hospital, China.

\section{Consent for publication}

All patients give my consent for information about myself to be published in Diagnostic Pathology.

\section{Competing interests}

The authors have no conflicts of interest to declare.

\section{Author details}

${ }^{1}$ Department of Obstetrics and Gynecology, Affiliated Hospital of Weifang Medical University, No. 2428, Yuhe Road, Weifang 261042, China.

2Department of Obstetrics and Gynecology, Beijing Chao-yang Hospital, Capital Medical University, No.8, North Road of Workers Stadium, Chaoyang District, Beijing 100020, China. ${ }^{3}$ Department of Pathology, Beijing Chao-yang Hospital, Capital Medical University, Beijing, China.

Received: 18 June 2020 Accepted: 1 February 2021

Published online: 19 February 2021

References

1. Arbyn M, Weiderpass E, Bruni L, de Sanjosé S, Saraiya M, Ferlay J, et al. Estimates of incidence and mortality of cervical cancer in 2018: a worldwide analysis. Lancet Glob Health. 2020;8(2):e191-e203. 
2. Bosch FX, Lorincz A, Muñoz N, Meijer C, Shah KV. The causal relation between human papillomavirus and cervical cancer. J Clin Pathol. 2002;55: 244-65

3 Darragh TM, Colgan TJ, Thomas Cox J, Heller DS, Henry MR, Luff RD, et al. The Lower Anogenital Squamous Terminology Standardization project for HPV-associated lesions: background and consensus recommendations from the College of American Pathologists and the American Society for Colposcopy and Cervical Pathology. Int J Gynecol Pathol. 2013;32:76-115.

4. de Sanjose S, Brotons M, Pavon MA. The natural history of human papillomavirus infection. Best Pract Res Clin Obstet Gynaecol. 2018:47:2-13.

5. Carreon JD, Sherman ME, Guillen D, Solomon D, Herrero R, Jeronimo J, et al. CIN2 is a much less reproducible and less valid diagnosis than CIN3: results from a histological review of population-based cervical samples. Int J Gynecol Pathol. 2007;26:441-6.

6. Dalla Palma P, Giorgi Rossi P, Collina G, Buccoliero AM, Ghiringhello B, Giliol $\mathrm{E}$, et al. The reproducibility of CIN diagnoses among different pathologists: data from histology reviews from a multicenter randomized study. Am J Clin Pathol. 2009;132:125-32.

7 Carozzi F, Confortini M, Dalla Palma P, Del Mistro A, Gillio-Tos A, De Marco $L$, et al. New Technologies for Cervival Cancer Screening (NTCC) working group use of p16-INK4A overexpression to increase the specificity of human papillomavirus testing: a nested substudy of the NTCC randomised controlled trial. Lancet Oncol. 2008;9:937-45.

8. Murphy N, Ring M, Killalea A, Uhlmann V, O'Donovan M, Mulcahy F, et al. p16INK4A as a marker for cervical dyskaryosis: CIN and CGIN in cervical biopsies and ThinPrep ${ }^{\text {TM }}$ smears. J Clin Pathol. 2003;56:56-63.

9. Horn L-C, Reichert A, Oster A, Arndal SF, Trunk MJ, Ridder R, et al. Immunostaining for p16INK4a used as a conjunctive tool improves interobserver agreement of the histologic diagnosis of cervical intraepithelial neoplasia. Am J Surg Pathol. 2008;32:502-12.

10 Guedes A, Brenna S, Coelho S, Martinez EZ, Syrjänen K, Zeferino L. p16INK4a expression does not predict the outcome of cervical intraepithelial neoplasia grade 2. Int J Gynecol Cancer. 2007;17:1099-103.

11. Sagasta A, Castillo P, Saco A, Torné A, Esteve R, Marimon L, et al. p16 staining has limited value in predicting the outcome of histological lowgrade squamous intraepithelial lesions of the cervix. Mod Pathol. 2016;29:51

12. Campbell LM, Pitta DR, De Assis AM, Derchain SFM, Campos EA, Sarian LOZ. Retrieval of HPV oncogenes E6 and E7 mRNA from cervical specimens using a manual open technology protocol. Springerplus. 2013;2:473.

13 Dockter J, Schroder A, Eaton B, Wang A, Sikhamsay N, Morales L, et al. Analytical characterization of the APTIMA ${ }^{\oplus}$ HPV assay. J Clin Virol. 2009; 45:39-47.

14. Cassidy A, Jones J. Developments in in situ hybridisation. Methods. 2014;70: 39-45.

15 Anderson CM, Zhang B, Miller M, Butko E, Wu X, Laver T, et al. Fully automated RNAscope in situ hybridization assays for formalin-fixed paraffinembedded cells and tissues. J Cell Biochem. 2016;117:2201-8.

16. Ukpo OC, Flanagan JJ, Ma X-J, Luo Y, Thorstad WL, Lewis JS. High-risk human papillomavirus E6/E7 mRNA detection by a novel in situ hybridization assay strongly correlates with p16 expression and patient outcomes in oropharyngeal squamous cell carcinoma. Am J Surg Pathol. 2011;35:1343-50

17 Mirghani H, Casiraghi O, Guerlain J, Amen F, He M-X, Ma X-J, et al. Diagnosis of HPV driven oropharyngeal cancers: comparing p16 based algorithms with the RNAscope HPV-test. Oral Oncol. 2016;62:101-8.

18. Nayar R, Wilbur DC. The Pap test and Bethesda 2014. Cancer Cytopathol. 2015;123:271-81.

19 Massad LS, Einstein MH, Huh WK, et al. 2012 updated consensus guidelines for the management of abnormal cervical cancer screening tests and cancer precursors. J Lower Genit Tract Dis. 2013;17:S1-27.

20. Graham SV. The human papillomavirus replication cycle, and its links to cancer progression: a comprehensive review. Clin Sci (Lond). 2017;131: 2201-21.

21 Wuerthner BA, Avila-Wallace M. Cervical cancer: screening, management, and prevention. Nurse Pract. 2016;41:18-23.

22 Kanthiya K, Khunnarong J, Tangjitgamol S, Puripat N, Tanvanich S. Expression of the 16 and Ki67 in cervical squamous intraepithelial lesions and cancer. Asian Pac J Cancer Prev. 2016:17:3201-6.

23. Wentzensen N, Schwartz L, Zuna RE, Smith KM, Mathews C, Gold MA, et al. Performance of p16/Ki-67 immunostaining to detect cervical cancer precursors in a colposcopy referral population. Clin Cancer Res. 2012;18:4154-62.
24 Martin C, Oleary JJ. Histology of cervical intraepithelial neoplasia and the role of biomarkers. Best Pract Res Clin Obstet Gynaecol. 2011;25:605-15.

25. Zafereo M, Xu L, Dahlstrom KR, Viamonte CA, Elnaggar AK, Wei Q, et al. Squamous cell carcinoma of the oral cavity often overexpresses p16 but is rarely driven by human papillomavirus. Oral Oncol. 2016;56:47-53.

26. Castle PE, Adcock R, Cuzick J, Wentzensen N, Torrezmartinez NE, Torres SM, et al. Relationships of p16 Immunohistochemistry and other biomarkers with diagnoses of cervical abnormalities: implications for LAST terminology. Arch Pathol Lab Med. 2020;144(6):725-34.

27. Liu YZ, Lu XP, Pan ZX, Zhang W, Chen ZR, Wang H, et al. Establishment of a novel method for primary culture of normal human cervical keratinocytes. Chin Med J. 2013;126:3344

28 Galgano MT, Castle PE, Atkins KA, Brix WK, Nassau SR, Stoler MH. Using biomarkers as objective standards in the diagnosis of cervical biopsies. Am J Surg Pathol. 2010;34:1077-87.

29. Scholzen T, Gerdes J. The Ki-67 protein: from the known and the unknown. J Cell Physiol. 2000;182:311-22.

30. Kruse A, Baak JPA, De Bruin PC, Jiwa M, Snijders W, Boodt PJ, et al. Ki67 immunoquantitation in cervical intraepithelial neoplasia (CIN): A sensitive marker for grading. J Pathol. 2001;193:48-54

31 Ikenberg H, Bergeron C, Schmidt D, Griesser H, Alameda F, Angeloni C, et al Screening for cervical cancer precursors with p16/Ki-67 dual-stained cytology: results of the PALMS study. J Natl Cancer Inst. 2013;105:1550-7.

32. Ozaki S, Zen Y, Inoue M. Biomarker expression in cervical intraepithelial neoplasia: potential progression predictive factors for low-grade lesions. Hum Pathol. 2011:42:1007-12.

33 Sobecki M, Mrouj K, Colinge J, Gerbe F, Jay P, Krasinska L, et al. Cell-cycle regulation accounts for variability in Ki-67 expression levels. Cancer Res. 2017;77:2722-34.

34. Doorbar J. Molecular biology of human papillomavirus infection and cervical cancer. Clin Sci. 2006:110:525-41.

35. Graham SV. The human papillomavirus replication cycle, and its links to cancer progression: a comprehensive review. Clin Sci. 2017:131:2201-21.

36. Evans MF, Peng Z, Clark KM, Adamson CS, Ma X, Wu X, et al. HPV E6/E7 RNA in situ hybridization signal patterns as biomarkers of three-tier cervical intraepithelial neoplasia grade. PLoS One. 2014;9(3):e91142.

37. Moscicki A, Ma Y, Wibbelsman C, Darragh TM, Powers A, Farhat S, et al. Rate of and risks for regression of cervical intraepithelial neoplasia 2 in adolescents and young women. Obstet Gynecol. 2010;116:1373-80.

38. Zeng SY, Liang MR, Li LY, Wu YY. Comparison of the efficacy and complications of different surgical methods for cervical intraepithelial neoplasia. Eur J Gynaecol Oncol. 2012;33:257.

39. Castle PE, Stoler MH, Solomon D, Schiffman M. The relationship of community biopsy-diagnosed cervical intraepithelial neoplasia grade 2 to the quality control pathology-reviewed diagnoses: an ALTS report. Am J Clin Pathol. 2007:127:805-15.

\section{Publisher's Note}

Springer Nature remains neutral with regard to jurisdictional claims in published maps and institutional affiliations.

Ready to submit your research? Choose BMC and benefit from:

- fast, convenient online submission

- thorough peer review by experienced researchers in your field

- rapid publication on acceptance

- support for research data, including large and complex data types

- gold Open Access which fosters wider collaboration and increased citations

- maximum visibility for your research: over $100 \mathrm{M}$ website views per year

At BMC, research is always in progress.

Learn more biomedcentral.com/submission 